\title{
Spinal Morphine-Induced Hypothermia Syndrome [SMHS]: A Different Type of Perioperative Hypothermia
}

\author{
William J Granger* \\ St. Joseph Regional Medical Center, USA
}

\begin{abstract}
This case report describes two more patients with the unusual side effect of spinal morphine-induced hypothermia. This side effect is more accurately defined as a syndrome consisting of hypothermia that is profound, refractory, and delayed in onset with paradoxical signs and symptoms, and psychological effects. The two cases presented here and previously published reports show a significant correlation not only with short stature $[<163 \mathrm{~cm}]$ and advancing [age $>28]$ maternal age, but also female gender, pregnancy, and Caesarean section. Older, shorter patients undergoing C-section may require more careful selection and monitoring if intrathecal morphine is employed for postoperative pain relief.
\end{abstract}

Keywords: SMHS, Hypothermia, Bupivacaine

\section{Introduction}

While spinal opioids for postoperative pain control came into general use in the early 1980 s, profound $\left[<34^{\circ} \mathrm{C}\right]$ hypothermia associated with intrathecal morphine was first reported in $1992^{1}$ with a total of 9 case reports [10 patients] in English ${ }^{1-6}$ and foreign language literature..$^{7-9}$ Mild hypothermia - not lower than $35.8^{\circ} \mathrm{C}-$ is an expected side effect of spinal analgesia with local anesthetics and results in an average drop of $0.76^{\circ} \mathrm{C}$ due to the sympatholytic effect of the local anesthetic. The addition of morphine further decreases body temperature to a total of $1.1^{\circ} \mathrm{C} .{ }^{10}$ These temperature decreases are usually of minor significance and easily treated using common rewarming methods.

Many case reports, however, show a more severe hypothermia that is best described as not just profound, but also refractory [to both active and passive warming], and delayed in onset [2-3 hours after intrathecal dose and resolved by 6 hours]. Perhaps most interesting are the paradoxical signs and symptoms of subjective warmth or euthermia while hypothermic, and concurrent shivering and sweating. In addition, patients have psychological aberrations ranging from anxiety, dysphoria, and restlessness to a floating sensation and tunnel vision. It may have been these latter symptoms that led clinicians to use lorazepam to successfully treat this side effect [instead of naloxone], although benzodiazepines are not normally considered to be opioid antagonists. Since this side effect is better described as a syndrome and has never been formally named, the acronym SMHS [for spinal morphine-induced hypothermia syndrome] will be used in this article to avoid confusion with the more routine hypothermia associated with intrathecal morphine use.

The author thanks both patients for providing written consent to access their medical records and to publish their stories.

\section{Case Report 1}

The patient was a 36-year-old ASA PS2 39-week $\mathrm{G}_{2} \mathrm{P}_{1}[150 \mathrm{~cm}$ height, $60 \mathrm{~kg}$ weight, and BMI 26.9] Caucasian for elective sterilization and repeat Caesarian section [C-section] initiated ahead of

\begin{tabular}{|l|l|}
\hline Quick Response Code: & *Corresponding author: William J Granger, 5215 Holy Cross Parkway, Mishawaka, IN 46545, \\
USA & Published: 10 September, 2021 \\
Received: 16 August, 2021 & Citation: Granger WJ. Spinal Morphine-Induced Hypothermia Syndrome [SMHS]: A Different \\
Type of Perioperative Hypothermia. SOJ Med Clin Case Rep. 2021;1(1):1-3. D0I: \\
10.53902/SOJMCCR.2021.01.000504
\end{tabular}


schedule due to early onset of labor. Her past medical history was unremarkable as was her pregnancy. At 1740 hours, a spinal anesthetic [via $25 \mathrm{G}$ Whitacre needle, median approach at $\mathrm{L}_{3-4}$, sitting position] was initiated with $15 \mathrm{mg}$ bupivacaine $0.75 \%$ in $\mathrm{D}_{8.25} \mathrm{~W}$ with $0.2 \mathrm{mg}$ preservative-free morphine sulfate [MS-PF]. Incision was made at 1758 hours and at 1808 hours a living male was delivered. A forced air warming device was applied after induction and the patient arrived in PACU at 1919 hours with a temporal temperature of $36.1^{\circ} \mathrm{C}$. She was received back on the floor at 2010 hours, and two nurses were unable to obtain an oral or temporal temperature to register. An axillary temperature of $34.2^{\circ} \mathrm{C}$ was finally obtained, and the patient was given warmed IV fluids and several warm blankets. At 2100, 2210, 2305, and 2325 hours, her temperature remained at $34.5^{\circ} \mathrm{C}$ orally despite continued warming attempts. From 0010 to 0435 hours, her temperature increased and hovered around $36.3^{\circ} \mathrm{C}$ orally. The remainder of her hospital course was unremarkable, and she was discharged on the third postoperative day.

On post discharge interview, the patient described fatigue in the OR, but when she got to the PACU, it had resolved. Returning to the maternity floor, however, she felt "hot" [even though temperature was $34.2^{\circ} \mathrm{C}$ ] with shivering and sweating at the same time and an "out of body experience that wasn't". When asked to elaborate, she described feeling "extremely lightweight". Another unusual experience was "seeing all the faces of her visitors merge into one." She was pleased with her postoperative pain relief and denied any other side effects except mild nausea.

\section{Case Report 2}

The patient was a 41-year-old Caucasian $\mathrm{G}_{8} \mathrm{P}_{4}$ [Height $159 \mathrm{~cm}$, weight $79.8 \mathrm{~kg}$, BMI 31.2] for elective sterilization and repeat elective C-section. Her past medical history and pregnancy were unremarkable. She was brought to the OR, and at 0752 hours, a spinal anesthetic [via 25G Whitacre needle, $\mathrm{L}_{3-4}$ median approach, sitting position] was initiated using $12 \mathrm{mg}$ bupivacaine in $\mathrm{D}_{8.25} \mathrm{~W}, 0.2 \mathrm{mg}$ MS-PF, and 50mcg epinephrine. The anesthetic and surgery were unremarkable and she delivered a living female infant. At 0904 hours, the patient was transferred to PACU with stable vital signs and a temporal temperature of $36.1^{\circ} \mathrm{C}$. The patient complained of a cold sensation, so she was given a warm blanket which made her feel euthermic. She was transferred back to the floor around 0948 hours and began to feel progressively colder yet had paradoxical sweating. This sensation lasted a brief time and then she was just cold. She stated she only had shivering when she was sweating. Multiple attempts with different measuring devices finally yielded an oral temperature of $34.0^{\circ} \mathrm{C}$. By 1400 hours, her temperature had increased to $35.3^{\circ} \mathrm{C}$. At 1800 hours, a decision was made to transfer her to the ICU for hypotension, hypothermia and bradycardia. Her systolic BP was around $100 \mathrm{~mm} \mathrm{Hg}$ and pulse was $53 \mathrm{bpm}$ with a temporal temperature of $35.3^{\circ}$ C. On arrival to the ICU at 1900 hours, her temperature was $36^{\circ} \mathrm{C}$ orally and continued to increase through the night as did her blood pressure and heart rate. Her treatment in the ICU consisted of a liter of normal saline and more warm blankets. She was transferred back to the maternity unit the next morning, and the remainder of her stay was uneventful. She admitted to good postoperative pain relief and only some minor itching as a side effect. Post-discharge interview revealed no additional information.

\section{Discussion}

A simple perusal of the two cases reveals two common features: short stature and advanced maternal age. No other case report of SMHS specifically mentions either one. In fact, 3 of the case reports do not even provide the height in the case summary. Additionally, an observational study ${ }^{11}$ could not find any demographic differences between the normothermic, hypothermic and "symptomatic" [likely SMHS subjects] groups ( $\mathrm{P}>0.05)$, even though their own data showed the symptomatic group to be $2 \mathrm{~cm}$ shorter than the other two groups. However, when comparing the other case reports, 7 out of 8 patients were below the average height for a woman $[163 \mathrm{~cm}]$, and simple statistical testing (sign test) reveals a $P$ value of 0.035 which is significant $(\mathrm{P} \leq 0.05)$. The one case report involving a male patient ${ }^{1}$ did not give a height but did give a weight of $43 \mathrm{~kg}$, and his height would still be below average even with a BMI of 18 .

Similarly, for advanced maternal age there is only one other case report with a patient age over 35; however, if one uses the average maternal age of 28 (CDC/NCHS) instead, 9 out of 10 were older $(\mathrm{P}=0.01)$. Another study which looked at predictors of hypothermia ${ }^{12}$ determined that high spinal and advanced age are the only significant predictors $(\mathrm{P} \leq 0.05)$. Female gender, pregnancy, and the type of operation [C-section] are three common features in the case reports: 11 out of 12 [13] were female $(\mathrm{P}=0.003)$ [0.011], and 10 out of 12 [13] cases were C-sections ( $\mathrm{P}=0.019)$ [0.046], both of which are significant. All the C-sections would naturally involve pregnant female patients, but surgeries in pregnant patients other than C-sections, especially using intrathecal morphine, are uncommon. On the other hand, over the past 30 years there have been a wide variety of surgical procedures in both sexes, some exclusively male, involving intrathecal morphine, so one would expect to see SMHS in male patients and operations other than C-sections. Still there is only one non-obstetric case ${ }^{5}$ [total knee arthroplasty] and one case [skin grafting] involving a male patient. ${ }^{1}$

Since the putative mechanism of SMHS involves morphine reaching the $\delta$-opioid receptors in the dorsal medial hypothalamus, it would stand to reason that any factor that increases the cephalad spread of morphine would correlate with the incidence of this side effect. One review article ${ }^{13}$ gives numerous factors related to increasing cephalad spread: these include increasing age, decreased patient height, female gender, decreased CSF density, reduction in 
CSF volume, and effect of progesterone increasing neuronal sensitivity. The last three factors in particular are related to pregnancy, and the first three to case reports of SMHS. This study also makes the argument that height, in and of itself, is not the important factor but the distance from injection site to $\mathrm{C} 7$ (which is never routinely measured in clinical practice).

Three questions remain:

1) Is SMHS a unique syndrome caused by a "perfect storm" of factors or is it simply an outlier on the continuum of hypothermia caused by intrathecal morphine use?

2) Which factor or combination of factors predisposes to SMHS and what is the relative risk of each factor?

3) Could histamine release from morphine activate another receptor such as $\mathrm{GABA}_{\mathrm{A}}$ in the brain?

As post-operative pain relief moves from centrally mediated drug therapy to peripheral conduction blockade, the incidence of SMHS should continue to decline, and its etiology may forever remain an enigma.

In summary, these two case reports along with previously published ones show a significant correlation of SMHS with short stature $(<163 \mathrm{~cm})$, advancing maternal age $(>28)$, female gender, and $\mathrm{C}$-sections. It should behoove the clinician to carefully consider the use of intrathecal morphine in this patient subset especially in light of an ongoing trend for delayed childbearing.

\section{Acknowledgments}

None.

\section{Funding}

None.

\section{Conflicts of Interest}

Author declares that there is no conflict of interest.

\section{References}

1. Kosai K, Takasaki M, Kawasaki H, et al. Hypothermia associated with intrathecal morphine. J Anesth. 1992;6:349-352.

2. Wishaw K. Hypothermia associated with subarachnoid morphine. Anaesth Intensive Care. 1997;25:586

3. Sayyid S, Jabbour D, Baraka A. Hypothermia and excessive sweating following intrathecal morphine in a parturient undergoing cesarean delivery. Reg Anesth Pain Med. 2003;28:140-143.

4. Valente A, Ciano F, Suppa E, et al. Hypothermia after cesarean section with combined spinal-epidural anesthesia and postoperative epidural analgesia. Int J Obstet Anesth. 2008;17:78.

5. Ryan K, Price J, Warriner C, et al. Persistent hypothermia after intrathecal morphine: case report and literature review. Can J Anaesth. 2012;59(4):384-388.

6. Mach J, Van Havel T, Gadwood J, et al. Intrathecal opioid-induced hypothermia following subarachnoid block with morphine injection for elective cesarean delivery: a case report. AANA J. 2016;84:23-26.

7. Peillon P, Dounas $\mathrm{M}$, Lebonhomme J, et al. Hypothermie sévère au décours de césariennes sous rachianesthésie. Ann Fr Anesth Réanim. 2002;21:299-302.

8. Fischer M, Dequiré, Kalem A, et al. Hypothermia after spinal anaesthesia: implication of morphine? Ann Fr Anesth Réanim. 2006;25:296298.

9. Harkouk H, DePréville G, Benhamou D. Profound hypothermia after spinal anesthesia and intrathecal morphine after caesarian: a new case report. Ann Fr Anesth Réanim. 2013;32:53-55.

10. Hui C, Huang $C$, Lin $C$, et al. A randomized double-blind controlled study evaluating the hypothermic effect of $150 \mu \mathrm{g}$ morphine during spinal anaesthesia for caesarean section. Anaesthesia. 2006;61:29-31.

11. Hess P, Snowman C, Wang J. Hypothermia after cesarean delivery and its reversal with lorazepam. Int J Obstet Anesth. 2005;14:279-283.

12. Frank S, El Rahmany H, Cattaneo C, Barnes R. Predictors of hypothermia during spinal anesthesia. Anesthesiology. 2000;92:1330-1334.

13. Hocking G, Wildsmith JA. Intrathecal drug spread. Br J Anaesth. 2004;93:568-578. 